\title{
How does role accumulation enhance career adaptability? A dual mediation analysis
}

\author{
Qingqing Feng ${ }^{1}\left[\right.$ Xiaoxi Chen $^{1}\left[\right.$ Zexian Guo $^{1}$
}

Accepted: 9 September 2021

(c) The Author(s), under exclusive licence to Springer Science+Business Media, LLC, part of Springer Nature 2021

\begin{abstract}
Investigating the contributing factors of career adaptability has always been an important topic in the field of vocational psychology research. From the perspective of person-environment interaction, this study introduced the role accumulation theory into the researches of career adaptability. Using a sample of 379 Chinese college students (mean age $=20.36$ years, $\mathrm{SD}=1.67$ ), a model of role accumulation affecting college students' career adaptability was constructed, and the parallel mediating mechanisms of self-efficacy and social support were also discussed. Participants filled out questionnaires regarding role accumulation, self-efficacy, social support, and career adaptability. The results of structural equation modeling (SEM) showed that: (1) Role accumulation positively predicted career adaptability in college students; (2) Role accumulation also indirectly predicted career adaptability through self-efficacy and social support. The present study is the first to validate the psychological pathways linking role accumulation to career adaptability via self-efficacy and social support. The contribution of this study to the literature is to provide a new perspective that can clarify the predictors of career adaptability. In addition, for educational administrators and career practitioners, targeting role accumulation is valuable for developing college students' career adaptability.
\end{abstract}

Keywords Role accumulation $\cdot$ Self-efficacy $\cdot$ Social support $\cdot$ Career adaptability $\cdot$ Emerging adults

\section{Introduction}

UN Secretary-General António Guterres pointed out at the World Health Summit that due to the COVID-19 pandemic and the economic recession, about 500 million jobs worldwide disappeared in 2020 (UN News, 2020). At the same time, China's college graduates reached 8.74 million in 2020, an increase of 400,000 year-on-year (Xinhua News Agency, 2020). The unstable economic environment, the sharp decrease in the recruitment demand and fierce competition in the talent market have all made the employment situation of college graduates increasingly severe. In the face of unknown employment pressure and risks, it is crucial that

Xiaoxi Chen

txiaoxi@jnu.edu.cn

Qingqing Feng

17864195061@163.com

Zexian Guo

1724275572@qq.com

1 School of Management, Jinan University, 510632 Guangzhou, China individuals must develop the ability to adapt to the requirements and needs of career development (Hou et al., 2012; Johnston, 2018), which also puts forward new challenges for college career management education. Therefore, it is urgent to explore the mechanism for improving college students' career adaptability (Guan et al., 2013).

Career adaptability refers to an individual's readiness for coping with predictable career tasks, career roles involved, and unpredictable adjustments brought by changes in the working and working environment (Savickas, 1997). Providing college students with career adaptability resources can significantly increase their chances of finding high-quality jobs in the future (Guan et al., 2013; Koen et al., 2012). Previous studies regarding to the contributing factors to career adaptability have primarily focused on three aspects: demographic factors (such as gender, age, education, and immigration background; e.g. Hirschi, 2009; Zacher, 2014), personality factors (such as big-five personality, within-person flexibility, approach/avoidance traits; e.g. Chong \& Leong, 2015; Guan et al., 2017; Storme et al., 2020), and family factors (such as family socioeconomic status and parental educational level; e.g. Hirschi, 2009; Wu, 2008), which 
are more unchangeable, unlearnable and passive, cannot bring practical suggestions for career guidance and counseling techniques. In fact, career adaptability is not a stable and unchanging trait (Savickas \& Porfeli, 2012; Zacher, 2014). On the contrary, it may change with time and situations, and can be influenced by interactions between the person and the environment and developed through education and experiences (Savickas \& Porfeli, 2012). Thus, a more dynamic perspective to understand the antecedents of career adaptability was needed. In addition, previous studies often focused on single aspects of predictors of career adaptability (e.g., support from family and close friends, Kenny \& Bledsoe, 2005; training courses from school, Koen et al., 2012), however, little work was done with a more comprehensive view which including more integrative factors (Chong \& Leong, 2015; Hirschi, 2009).

Role accumulation theory can provide a new useful reference to address above limitations. Role accumulation represents the diversity of social roles assumed by individuals. The more roles there are, the closer an individual links to society and the more frequently he or she interacts with the environment (Lang \& Lee, 2005). The measurement of role accumulation involves various aspects (such as family factors, school factors and social factors) of the interaction between individuals and environment, which is a dynamic and comprehensive perspective to understand the possible predictors of career adaptability development. According to the role accumulation theory, participation in multiple roles brings a series of benefits to individuals, such as obtaining role privileges, maintaining overall status security, providing resources for enhancing role performance, and promoting self-satisfaction and personality perfection (Sieber, 1974). Therefore, based on the role enhancement perspective, this study aimed to explore the influence of role accumulation on college students' career adaptability. Role accumulation theory believes that the process of participation and experience of multiple roles enhances the individual's belief in life control. Hirschi (2009) proposed that agency beliefs are important predictors of career adaptability, including capability beliefs and context beliefs. The former refers to the individual's perception of his or her own ability, that is, general self-efficacy, and the latter refers to the sense of support from the surrounding environment, that is, social support. Thus, we assumed that role accumulation may relate to career adaptability through their impacts on individuals' self-efficacy (capability belief) and social support (context belief). Therefore, the second aim of this study is to investigate the parallel mediating effects of self-efficacy and social support.

The present study contributes to the extant literature on role accumulation and career adaptability in several ways. First, compared with the fruitful empirical evidence on the consequences of career adaptability, knowledge about the antecedents of career adaptability is limited (Bocciardi et al., 2017; Rasheed et al., 2021), especially by an interactive and dynamic perspective. Considering that career adaptability is not a fixed trait but influenced by the interplay of individuals and external circumstances (Bocciardi et al., 2017), our study uses role accumulation to represent the extent to which individuals interact with their external environment, and identifies role accumulation as an important determinant propelling the development of career adaptability. In doing so, our research offers a novel view on how individuals gain career adaptability resources through an interactive process. In addition, the variable role accumulation provides an integrative perspective as it can represent the interaction of individuals at different contextual levels (such as family, school, and organization) rather than a specific aspect, which adds new knowledge and echoes Chong and Leong's call for more research considering including more social and environment factors (2015). Second, our examination of parallel mediation mechanisms helps to open the black box of how role accumulation shapes individuals' career adaptability, indicating that through frequent interactions with the environment, individuals can enhance their capability belief (self-efficacy) and context belief (social support), and then become more adaptive. Third, the current study extends the application of role accumulation theory as previous literature has rarely given attention to potential positive impacts of multiple roles involvement on college students. However, college years are an important period when an individual's role identity changes and expands. By identifying that multiple roles can benefit college students on their career adaptability, our research enriches the knowledge about the outcomes of role accumulation. From a practical point of view, career interventions targeting role accumulation are valuable for developing college students' career adaptability. The study offers some important practical implications for educational administrators and career practitioners to consider providing students with more opportunities to participate in various roles.

\section{Role Accumulation and Career Adaptability}

According to Arnett's theory of development from the late teens through the twenties, college students are in their emerging adulthood, a changeable and fluid period of life aged from 18 to 25 (Arnett, 2000). Emerging adults are common in industrialized countries, in which people always receive higher education in order to find better jobs. People in this stage have got rid of the control and restraint of their parents, and at the same time postponed adult responsibilities (Murphy et al., 2010), so they have enough opportunities to try and explore. As the process of China's industrialization accelerates, emerging adulthood also appears on its young people. During their college years, Chinese emerging 
adults have enough opportunities to experience a wide range of personal activities and explore various possible life directions (Arnett, 2000). In addition to learning, they also have opportunities to participate in various clubs, party member activities, part-time jobs, and social activities. Therefore, a college student may simultaneously assume multiple roles such as students, party members, interns, and romantic partners.

According to role accumulation theory, participating in multiple roles is like putting eggs in multiple baskets, which will bring a series of benefits to individuals rather than losses (Baruch \& Barnett, 1986). One benefit is that multiple roles play a buffer role in maintaining the overall status of individuals. Individual's failure in a particular field or relationship can be compensated alternatively by other role experiences (Kulik et al., 2015; Sieber, 1974). Resources from one role can also be used to meet the needs of another role (Greenhaus \& Powell, 2006; Marks, 1977). This accumulation of emotions or resources as a result of participating in multiple roles can serve as an important buffer especially for those who are experiencing fear or expectations of failure in the face of unpredictable situations and uncontrollable changes in a particular role relationship. Therefore, it is believed that individuals involved in multiple roles will be more adaptive due to more buffer resources accumulation when facing unpredictable career environment changes. Furthermore, the literature on career adaptability also shows that when individuals focus on grasping different roles rather than a fixed role leading to the final goal, their career adaptability will be stronger (Van Vianen et al., 2009). The wide range of experience developed from a variety of activities in the early stages is essential for individuals' future careers. Therefore, we proposed:

H1: Role accumulation positively predicts the individual's career adaptability, the more roles an individual assumes, the better his or her career adaptability.

\section{The Mediating Role of Self-efficacy}

Self-efficacy represents an individual's belief or inference about the ability to complete a certain behavior (Bandura, 1998). According to the role accumulation theory, participating in multiple roles means that individuals have many sources of stimulation, from which they will get more satisfaction and social identity, and thus more psychological resources (Baruch \& Barnett, 1986).Commitment to multiple roles provides more opportunities for positive selfexperience and verification (Marks \& MacDermid, 1996), enabling individuals to feel their own potential, enhance their sense of self-worth and life meaning (Greenhaus \& Powell, 2006). Previous research has shown that women who played multiple roles had more opportunities to feel good about themselves and activities they engage in (Ruderman et al., 2002), and the positive emotional experience gained from roles can enhance their confidence in other role tasks. Therefore, it is possible that role accumulation positively predicts individuals' self-efficacy, and people with more roles may have higher self-efficacy.

Furthermore, due to the positive experience gained from the participation of multiple roles, people firmly believe that "they have the right to make an influence through their actions". Individuals with a strong sense of self-efficacy can timely and effectively perceive and understand environmental changes, predict positive future work scenarios, adjust their own actions, persevere in the face of difficulties, and thus show strong adaptability when facing the unknown and unpredictable career environment (Bandura, 1997; Bandura et al., 2001). A study of children showed that perceived career self-efficacy provides guidance for children's career pursuits, enabling them to take their life's work seriously (Bandura et al., 2001). Another study conducted on college students found that when faced with an unknown and challenging environment, students with high self-efficacy can create more adaptive environments for themselves, and therefore are more likely to produce adaptive responses (Meng et al., 2012). Therefore, it is possible that self-efficacy positively influences individuals' career adaptability. Taking together, we proposed the following hypothesis:

$\mathrm{H} 2$ : Self-efficacy mediates the relationship between role accumulation and career adaptability.

\section{The Mediating Role of Social Support}

Social support refers to the spiritual or material help that an individual receives through social connections with various social persons (e.g., relatives, friends, colleagues) and social organizations (family, community, etc., Ye \& Dai, 2008). Role accumulation theory suggests that having multiple roles facilitates individuals to expand their social networks (Lang \& Lee, 2005), allowing them to engage and interact with more role partners and thus gain additional benefits, such as being invited to social gatherings and meeting third parties that are helpful for career development. These byproducts of the social relationships brought by role accumulation (Sieber, 1974) constitute social support resources for career adaptability development, including emotional support such as encouragement and comfort from friends and family, and instrumental support such as obtaining valuable career information through a wide range of information channels. As Ruderman et al. (2002) showed, commitment to multiple roles can increase psychological and social support resources of female managers, which in turn enhances their 
leadership. Therefore, it is believed that role accumulation positively predicts individuals' social support perceptions.

As a protective situational resource, social support resources can have a positive impact on individuals' ability to adapt. Social support resources gained from one role can be transferred to the development of another role; on the one hand, emotional support such as support from parents, friends or significant others helps to create a positive emotional climate, relieves anxiety and stress, and helps individuals to cope with changes and challenges in the work environment (Ataç et al., 2018; Butterfield et al, 2010); on the other hand, instrumental support gained from various social relationships are beneficial to individuals' career development, one such example is that they can obtain potential employment opportunities and receive career guidance from significant others for their own career role development and advancement (Kracke, 2002; Seibert et al., 2001). Maintaining a wide range of social relationships is necessary to strengthen an individual's status (Sieber, 1974), and the supportive interpersonal relationships that individuals develop as a result of participating in multiple roles can be a potential resource for overcoming challenges and adapting to career circumstances (Kenny \& Bledsoe, 2005). Therefore, social support may have a positive impact on individuals' career adaptability. The more social support an individual perceives, the fewer psychological adjustment problems he or she will have (Fan, et al., 2012). Taking together, we proposed that:

H3: Social support mediates the relationship between role accumulation and career adaptability.

In summary, this study aimed to investigate the influence of role accumulation on college students' career adaptability and the parallel mediating role of self-efficacy and social support in it, and Fig. 1 shows the research proposed model.

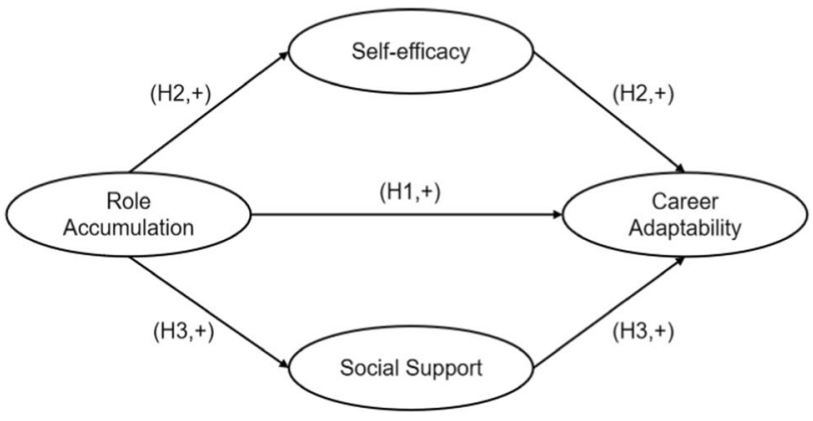

Fig. 1 Illustration of the proposed parallel mediation model

\section{Methods}

\section{Participants}

The convenience sampling method was used to distribute the questionnaire link to college students in South China through the www.wjx.cn, an online platform that provides functions of creating questionnaires and collecting data. 392 questionnaires were received in the background but 379 were determined to be valid $(96.7 \%)$ due to eliminating the data with abnormal answer time and repeatedly choosing the same option. The remaining participants included 172 male students (45.4\%) and 207 female students (54.6\%), with a mean age of $20.36(\mathrm{SD}=1.67)$. The grade distribution of the participants was as follows: freshmen $(20.1 \%)$, sophomores (24.8\%), juniors (25.6\%) and seniors (29.6\%).

\section{Measures}

\section{Role Accumulation}

Taking the number of roles a college student occupied as the operational definition of role accumulation, participants were presented with a list of 11 different roles: student role (this role is mandatory); club or student organization's membership role; part-time job (internship) role; family (children) role; online role (meaning playing some special roles on the Internet, such as blogger, public content operator, etc.); party member role; researcher role (participating in teacher's project, etc.); student leader role; lover role; friend role; and other roles (adapted from Zhang, 2012). Participants were asked to answer whether they had participated in each specific role using a dichotomous scale of "0" (for "not occupied") and "1" (for "occupied") (Kulik et al., 2015). Participants' scores for this part of the question were equal to the number of roles they were involved during their college years, thus the role accumulation variable ranges from 1 to 11 in value (e.g., Baruch \& Barnett, 1986; Kulik \& Liberman, 2013; Lang \& Lee, 2005; Thoits, 1983).

\section{Self-Efficacy}

We assessed individuals' self-efficacy levels with a 10-item General Self-Efficacy Scale (GSES), which was developed by Schwarzer et al. (1997) and revised by Wang et al. (2001). One sample item was "I can always solve problems if I try hard enough ". All items are Likert scaled (5 points) with anchors of "strongly disagree" and "strongly agree". The higher the total score, the higher the self-efficacy levels. In the present study, the Cronbach's alpha was 0.94. 


\section{Social Support}

We assessed individuals' social support perceptions with a 17-item Adolescence Social Support Scale (Ye et al., 2008), including three dimensions of subjective support, objective support, and support utilization (Xiao, 1994). One sample item was "When faced with a dilemma, I will actively seek help from others ". All items are Likert scaled (5 points) with anchors of "strongly disagree" and "strongly agree". The higher the total score, the higher the level of perceptions of social support. The scale has been shown to have a good validity in the sample of college students (e.g., He et al., 2020; Jiang \& Bai, 2014). In the present study, the Cronbach's alpha was 0.96 .

\section{Career Adaptability}

We assessed individuals' career adaptability with a 24-item Career Adapt-Abilities Scale-China Form, which was developed by Savickas and Porfeli (2012) and revised by Hou et al. (2012), including four dimensions of career concern, career control, career curiosity, and career confidence. One sample item was " I will think about what my future will be like". A 5-point Likert scale was used to assess the degree of each specific ability individuals developed, ranging from"1" (for "not strong") to "5" (for "very strong"). In the present study, the Cronbach's alpha was 0.97.

\section{Control Variables}

Participants' age, gender and grade were assessed as control variables.

\section{Statistical Analysis}

The study used SPSS 26.0 to perform descriptive statistics and correlations analyses, and used Mplus 7 to conduct confirmatory factor analysis, and then constructed a structural equation model to analyze and test the proposed multiple parallel mediation model.

\section{Results}

\section{Common-Method Bias Test}

The common-method bias was tested using confirmatory factor analysis (CFA), a type of Harman's one-factor test, which considers common method bias to be less severe if the one-factor model is the worst fit compared to other competing models with multiple factors (Tang \& Wen, 2020). We used goodness of fit index to evaluate model fit. Some popular fit indexes are recommended in practice, including Root Mean Square Error of Approximation (RMSEA), Standardized Root Mean Square Residual (SRMR) and Tucker and Lewis Index (TLI) (Wen \& Liang, 2015). It is generally believed that when the absolute fit index RMSEA and SRMR are less than 0.08 , and the relative fit index TLI is more than 0.9, the model is acceptable (Hu \& Bentler, 1999; Wen \& Liang, 2015). Since the independent variable role accumulation has only one measurement indicators (i.e., the number of roles involved), it was not included in the confirmatory factor analysis. As shown in Table 1, the three-factor measurement model fits the data best and the one-factor model fits the data worst among the competing models. Thus, there was no obvious common-method bias and no covariance in this study.

\section{Descriptive Statistics and Correlation Analysis}

Table 2 shows the mean, standard deviations and intercorrelations of the study variables. The role accumulation was significantly positively related to self-efficacy $(r=0.64$, $p<0.01)$, social support $(r=0.54, p<0.01)$, and career adaptability $(r=0.61, p<0.01)$; and career adaptability was significantly positively related to self-efficacy $(r=0.88$, $p<0.01)$ and social support $(r=0.82, p<0.01)$.

\section{Mediation Analysis}

First, the direct effect of role accumulation on career adaptability was examined, the role accumulation was positively related to career adaptability $(\beta=0.60, p<0.001)$, thus supporting hypothesis 1 . Then, two mediating

Table 1 Results of confirmatory factor analysis

\begin{tabular}{|c|c|c|c|c|c|c|}
\hline Measurement models & $\chi^{2}$ & $d f$ & $\chi^{2} / d f$ & TLI & RMSEA & SRMR \\
\hline Three-factor(social support, self-efficacy and career adaptability) & 70.49 & 32 & $2.20^{* * * *}$ & 0.99 & 0.06 & 0.01 \\
\hline Two-factor(combined social support and self-efficacy into one factor) & 387.44 & 34 & $11.40^{* * *}$ & 0.90 & 0.17 & 0.04 \\
\hline $\begin{array}{l}\text { One-factor(combined social support, self-efficacy and career adaptability } \\
\text { into one factor) }\end{array}$ & 473.55 & 35 & $13.53^{* * *}$ & 0.88 & 0.18 & 0.04 \\
\hline
\end{tabular}

Note:n $=379,{ }^{* * *} p<0.001$. 
Table 2 Summary statistics and correlations

\begin{tabular}{|c|c|c|c|c|c|c|c|c|c|}
\hline Variables & $M$ & $S D$ & 1 & 2 & 3 & 4 & 5 & 6 & 7 \\
\hline 1 Gender $^{\mathrm{a}}$ & - & - & - & & & & & & \\
\hline 2 Age & 20.36 & 1.67 & $0.13^{*}$ & - & & & & & \\
\hline 3 Grade & 2.65 & 1.11 & 0.08 & $0.80^{* *}$ & - & & & & \\
\hline 4 Role accumulation & 6.79 & 1.85 & 0.05 & $0.16^{* *}$ & $0.29^{* *}$ & - & & & \\
\hline 5 Self-efficacy & 37.80 & 8.11 & 0.05 & $0.14^{* *}$ & $0.22^{* *}$ & $0.64^{* *}$ & - & & \\
\hline 6 Social support & 65.84 & 13.58 & -0.02 & $0.23^{* *}$ & $0.26^{* *}$ & $0.54^{* *}$ & $0.77^{* *}$ & - & \\
\hline 7 Career adaptability & 93.60 & 17.62 & 0.02 & $0.28^{* *}$ & $0.30^{* * *}$ & $0.61^{* *}$ & $0.88^{* *}$ & $0.82^{* *}$ & - \\
\hline
\end{tabular}

Note: ${ }^{\mathrm{a} G e n d e r}$ as a dummy variable, female $=0$, male $=1 ; \mathrm{n}=379,{ }^{*} p<0.05,{ }^{* *} p<0.01$. variables-self-efficacy and social support-were entered into the model to test whether they mediated the relationship between role accumulation and career adaptability. Ten items of self-efficacy were assigned into three parcels of self-efficacy; subjective support, objective support, and support utilization as three parcels of social support; and career concern, career curiosity, career confidence, and career control as four parcels of career adaptability; role accumulation was directly included in the model as an observed indicator rather than a latent variable as it is a count variable. The full model demonstrated an acceptable fit to the data, $\chi^{2} / \mathrm{df}=5.23, \mathrm{CFI}=0.95$, TLI $=0.93$, RMSEA $=0.11$. The results of the specific path analysis are shown in Fig. 2.
The positive predictive effect of role accumulation on self-efficacy $(\beta=0.65, p<0.001)$ and social support $(\beta=0.54, p<0.001)$ was significant, and the predictive effect of social support $(\beta=0.38, p<0.001)$ and self-efficacy ( $\beta=0.72, p<0.001)$ on career adaptability was significant. The direct effect of role accumulation on career adaptability was not significant $(\beta=-0.01, p>0.05)$, indicating that self-efficacy and social support fully mediated the relationship between role accumulation and career adaptability. Furthermore, we conducted Bias-Corrected Bootstrap analyses, which is useful in forming confidence interval (Bollen \& Stine, 1990), to repeat the sampling 5000 times to examine the significance of indirect effects. Specifically, if the 95\% confidence interval does not include zero, the mediation

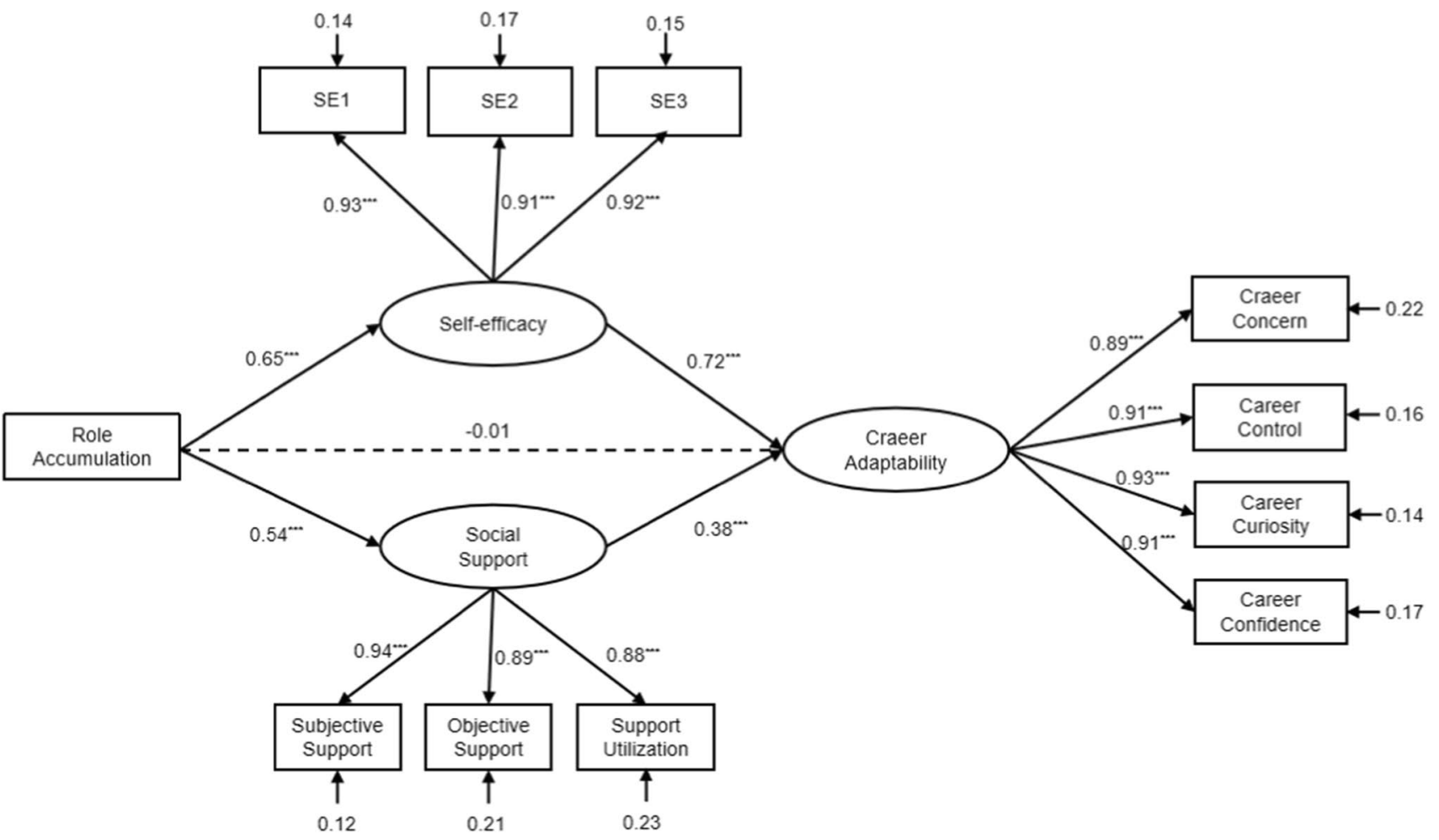

Fig.2 Parallel mediation models with standardized regression coefficients and residual variances 
effect hypothesis is supported. Bootstrapping results are shown in Table 3, the mediation effect of self-efficacy (95\%CI, $[0.385,0.538])$ and social support (95\% CI, [0.113, $0.299]$ ) are significant, thus supporting $\mathrm{H} 2$ and $\mathrm{H} 3$. As a whole, all hypotheses in this study were supported.

\section{Discussion}

The main aim of the study was to test if and how role accumulation influences career adaptability and the findings supported the hypothesized dual mediation model. The results showed that role accumulation has a positive effect on college students' career adaptability, that is, the more roles a person assumed, the better his/her career adaptability. And in accordance with our expectations, self-efficacy and social support were found to mediate such a relationship in a parallel way. These findings are in line with previous research demonstrating that holding multiple roles brings individuals psychological benefits and then helps to achieve positive career outcomes (such as lower job stress, Lang \& Lee, 2005; enhance work effectiveness, Ruderman et al., 2002).

One of the main findings of the study is that role accumulation is a positively significant predictor of career adaptability, which is to say, for students, the gains and resources from participating in different kinds of roles (such as family, school, and internship roles) can help them to be more adaptive in future careers. Prior to this, very limited studies have proposed the possibility that college students' personal experiences (e.g. internship, clubs, or student leaders experiences) may enhance their own career adaptability (CelenDemirtas et al., 2015; Mai, 2017; Tian \& Fan, 2014) but didn't have an in-depth explanation about why these specific activities can bring additional benefits. For example, a study which investigated associated factors of career adaptability among 431 student nurses found that student nurses with student leader experiences will get higher scores on career adaptability than student nurses who didn't serve as student leaders (Tian \& Fan, 2014). Extending these earlier findings,

Table 3 Bootstrapping results for indirect effects

\begin{tabular}{lllll}
\hline Path & Indirect estimate & S.E & \multicolumn{2}{l}{$95 \%$ CI } \\
\cline { 3 - 5 } & & & Lower & Upper \\
\hline $\begin{array}{l}\text { Total indirect } \\
\begin{array}{l}\text { Role accumula- } \\
\text { tion } \rightarrow \text { Self- }\end{array}\end{array}$ & 0.668 & 0.045 & 0.579 & 0.756 \\
$\begin{array}{l}\text { efficacy } \rightarrow \text { Career } \\
\text { adaptability }\end{array}$ & & 0.039 & 0.385 & 0.538 \\
$\begin{array}{l}\text { Role accumula- } \\
\text { tion } \rightarrow \text { Social } \\
\text { support } \rightarrow \text { Career } \\
\text { adaptability }\end{array}$ & 0.206 & & & \\
\hline
\end{tabular}

our study introduced the concept of role accumulation to explore the impact of personal activities on career adaptability based on arguments that social roles provide individuals with a framework for organizing personal activities (Boeri, 2004) and proved that students can gain more career adaptability resources by involving multiple roles and participating various curricular and extra-curricular activities.

Another important finding in this study is the parallel mediating effect of self-efficacy and social support. First, the present study found that self-efficacy mediates the relationship between role accumulation and career adaptability. Self-efficacy is a key resource that can be transferred across domains (Kelly et al., 2020), and the rich experiences accumulated from trying out and exploring different roles can enhance college students' beliefs about their ability to perform other tasks effectively. Moreover, competency belief, i.e. self-efficacy, is a key element in explaining individuals' career choices and development, and only when people believe that they can produce desired outcomes through their own actions will they be motivated to exert sufficient effort and resources to cope with difficulties and obstacles and ultimately reach adaptive goals (Bandura, 1997; Bandura et al., 2001). That is, the higher self-efficacy, the better career adaptability, which is in line with previous studies (e.g. Rasheed et al., 2021). The mediating role of self-efficacy proves that self-efficacy as an agency mechanism plays an important role in individuals' career management (Bandura et al., 2001). Second, the research also identified the mediating role of social support between role accumulation and career adaptability. Multiple roles involvement promotes individual's sense of social connection and enhances mental and material resources available to individuals from the external environment, which leads to a high level of social support perceptions. The positive association between role accumulation and social support is consistent with Ruderman's (2002) research findings that commitment to multiple roles provide women managers more social support resources. Moreover, social support positively predicted college students' career adaptability. Perceived social support can reduce individuals' perceptions of uncertainty and increase their sense of control over their environment (Albrecht \& Adelman, 1987; Rosenfeld et al., 2000), enabling them to be well prepared and comfortable in the face of unpredictable career changes (Zhang \& Li, 2020), thus promoting the development of career adaptability. In addition, compared to individualistic cultures, collectivist cultures focus more on social interactions (Wang \& Fu, 2015) and pursuing obtaining favorable resources from interpersonal relationships to solve problems; therefore, social support has an important impact on college students' career adaptability especially in a collectivist country like China. The positive and significant link between social support and career adaptability was in line with numerous previous research findings 
(e.g., Hirschi, 2009; Kenny \& Bledsoe, 2005; Öztemel \& Yildı-Akyol, 2019; Wang \& Fu, 2015).

\section{Theoretical Contributions and Practical Implications}

Our research contributed to the literature for some aspects. First, the findings of this research promote current theoretical development on role accumulation among various social groups. Social roles and the corresponding role responsibilities are regarded as opportunities to gain additional social capital in the form of economic and social resources (Black et al., 2009), which individuals can use to create a satisfactory self-image and life situation (Nordenmark, 2004). Early research on multiple roles began after women entered the labor market on a large scale (Brody, 1981) and mainly focused on potential impact of women's non-work and work roles (e.g., Baruch \& Barnett, 1986; Black et al., 2009; Ruderman et al., 2002). For example, previous research showed that women with multiple roles (such as mother, wife, employee) are more likely to have a low mortality (Martikainen, 1995) and high life satisfaction and selfacceptance (Ruderman et al., 2002). However, knowledge about the effects that role accumulation has on other social groups is limited. We argue that it is especially important to utilize role accumulation as a theoretical framework in emerging adults researches considering emerging adulthood is a critical period for individuals' identity exploration and accumulation (Arnett, 2000), our research linked emerging adults' role experiences during their school years with their future career development abilities and demonstrated that the college students can also benefit from social role accumulation. Multiple roles managed by college students can work simultaneously and complement each other (Kelly et al., 2020; Kulik et al., 2015; Marks, 1977), accumulating psychological and social resources for individuals to effectively cope with future career role changes or career transitions (Ruderman et al., 2002). The current study confirmed that role accumulation theory remains valid in the presence of career management of emerging adults, thus extending the boundaries of the application of role accumulation theory.

Second, this study contributed to the career adaptability literature by offering a novel and dynamic perspective to reveal contributing factors of career adaptability. Results of this study suggested that career adaptability can be beneficially enhanced by individuals' frequent interactions with the environment through the assumption of social roles, confirmed that it is equally important to consider whether and how interactive factors influence career adaptability. Our study thus helps to gain a more complete and balanced picture of the occurrence of career adaptability.

Third, this study contributed to the career adaptability literature by revealing the specific mechanism that affects individuals' career adaptability in the process of interactions with environment, which echoed Nicklin's (2020) call to explore how multiple roles affect college students. The present study suggested that both self-efficacy and social support functioned as mediators between role accumulation and career adaptability in a parallel way, which indicated that multiple roles involvement not only enhanced individuals' competence beliefs but also promoted available social support resources, thereby enhancing abilities to adapt to career challenges. These findings are consistent with Kracke's (2002) view that a combination of personal competence (self-efficacy in this study) and others' help (social support in this study) can help address career-related developmental tasks.

Finally, this study also contributed to the emerging adulthood literature to some extent. Most emerging adults were born after 2000-they are called "after 00" (Generation Z) in China. Young Chinese people in this period are often experiencing identity explorations and various possibilities of life, but also confronted with some developmental challenges such as identity crisis and a sense of confusion (Arnett, 2000, 2007). Considering the features of emerging adulthood, it, therefore, brings a question that whether such a period is experienced positively or negatively by people (Arnett, 2007). Through this study, we have proved that emerging adulthood is beneficial to most people as it provides an extended period for young people to continuously accumulate role experiences and obtain resources from it, thus finally have a better response to life challenges, which moves forward the development of emerging adulthood theory.

Study findings carry some practical implications for career practitioners and education administrators to consider role accumulation for improving college students' career adaptability. Preparing for future career prospects is one of the core developmental tasks of college students (Koen et al., 2012) and understanding the impact of college students' role accumulation on career adaptability can help us to properly construct and guide their practice activities during school, guiding students to see themselves as active participants in changes rather than passive recipients (Goodman, 1994). Previous research showed that recent graduates usually take longer time to find a suitable job and are more likely to be job maladjusted and underemployed than social job seekers, and that career adaptability training significantly improves their employment qualities (including indicators of job satisfaction, person-environment fit, and subjective career success; Koen et al., 2012). School guidance and counseling services have been proved to play a very important role in personal development of students but faced many challenges in practice (Arfasa \& Weldmeskel, 2020). To improve the quality of guidance and counseling services on college students' career management, school 
administrators firstly should take a series of strategies such as employing professional counselors and constructing effective evaluating programs (Arfasa \& Weldmeskel, 2020). Second, combined with the findings of this study, career counselors and practitioners should develop career adaptability training programs for college students from the perspective of role accumulation by building social practice platforms, organizing rich social practice activities, and providing more environmental stimulation for college students to create more opportunities for role participation and encourage new social roles. As previous study showed that several novel and interesting strategies (such as Graphic Novel, Mandalas, Resiliency Handbook) can be developed to build and maintain student resilience for their transition from secondary to post-secondary education (Gamble \& Crouse, 2020), we also encourage some novel and innovative techniques to provide college students more adaptability resources, such as role simulation activities, which is also an important technique in medical education (Lay-Khim \& BitLian, 2019). All these approaches can help college students to build and maintain career adaptability and better complete the "school-work" transitions in the future.

\section{Strengths and limitations}

A methodological strength of this study is the use of the structural equation modeling (SEM) approach with latent variables, which can improve the accuracy of hypothesized model testing by requiring a clear definition of constructs and assumed relationships between constructs (Bagozzi, 1980; Chau, 1997). The study also has some limitations. The first is that the study adopted a cross-sectional research method, with insufficient inference argumentation about causality. Future studies are recommended to replicate our findings by gathering data from two or three time points. Second, all variables in this study are self-reported by students, which may produce a common method bias (CMB). Although we conducted a confirmatory factor analysis (CFA) and found that the degree of CMB is acceptable, gathering data from multiple sources is still recommended in future studies, such as asking individuals' parents and career counselors to rate their career adaptability, because of the argument that the beforehand control is the best way to minimize common method variance (Tang \& Wen, 2020). Third, the measurement of role accumulation is not perfect as we only measured the number of roles individuals played to represent role accumulation. We didn't consider problems such as how much time individuals spent on each role and the quality of each role they played, which may have individual difference and have a predictive effect on career adaptability (Celen-Demirtas et al., 2015). We acknowledged this limitation and encouraged a more rigorous and comprehensive role accumulation measurement method in the future.

\section{Conclusion and Future Directions}

The study examined the relationships among role accumulation, self-efficacy, social support and career adaptability drawing upon role accumulation theory. Holding multiple roles facilitates college students' career adaptability resources. Moreover, self-efficacy and social support mediate such a relationship in a parallel way.

We offer some potential directions for future studies. First, based on the research finding that holding multiple roles can facilitate emerging adults' career adaptability, we encourage more in-depth discussions about the potential impacts of social roles on individuals' career development, such as whether there is the optimal combination of roles or the best number of roles that can maximize individuals' career adaptability. Second, in addition to the function of multiple roles involvement as a dynamic factor in predicting career adaptability, future work could consider other important environmental antecedents, such as task variety and person-environment fit perceptions.

Funding This research was funded by the National Natural Science Foundation of China (Grant No. 31970990 and 71701080).

Data Availability The datasets generated during and/or analyzed during the current study are available from the corresponding author on reasonable request.

\section{Declarations}

All procedures performed in studies involving human participants were in accordance with the ethical standards of the institutional research committee and with the 1964 Helsinki Declaration and its later amendments or comparable ethical standards.

Consent to Participate Informed consent was obtained from all individual participants included in the study.

Consent for Publication The participants have consented to the submission of their data to the journal.

Conflict of Interest The authors declare that they have no conflict of interest.

\section{References}

Albrecht, T. L., \& Adelman, M. B. (1987). Communicating social support: A theoretical perspective. In T. L. Albrecht \& M. B. Adelman (Eds.), Communicating social support (pp. 18-39). Sage.

Arfasa, A. J., \& Weldmeskel, F. M. (2020). Practices and challenges of guidance and counseling services in secondary schools. Emerging Science Journal, 4(3), 183-191. https://doi.org/10.28991/ esj-2020-01222

Arnett, J. J. (2000). Emerging adulthood: A theory of development from the late teens through the twenties. American Psychologist, 55(5), 469-480. https://doi.org/10.1037/0003-066X.55.5.469 
Arnett, J. J. (2007). Emerging Adulthood: What Is It, and What Is It Good For? Child Development Perspectives, 1(2), 68-73. https:// doi.org/10.1111/j.1750-8606.2007.00016.x

Ataç, L. O., Dirik, D., \& Tetik, H. T. (2018). Predicting career adaptability through self-esteem and social support: A research on young adults. International Journal for Educational and Vocational Guidance, 18, 45-61. https://doi.org/10.1007/s10775-017-9346-1

Bagozzi, R. P. (1980). Causal models in marketing. Wiley.

Bandura, A. (1997). Self-efficacy: The exercise of control. Freeman.

Bandura, A. (1998). Self-efficacy. In V. S. Ramachaudran (Ed.), Encyclopedia of human behavior (Vol. 4, pp. 71-81). Academic Press.

Bandura, A., Barbaranelli, C., Caprara, G. V., \& Pastoreli, C. (2001). Self-efficacy beliefs as shapers of children's aspirations and career trajectories. Child Development, 72(1), 187-206. https://doi.org/ 10.1111/1467-8624.00273

Baruch, G. K., \& Barnett, R. C. (1986). Role quality, multiple role involvement, and psychological well-being in midlife women. Journal of Personality and Social Psychology, 51(3), 578-585. https://doi.org/10.1037/0022-3514.51.3.578

Black, A. R., Murry, V. M. B., Cutrona, C. E., \& Chen, Y. F. (2009). Multiple roles, multiple lives: The protective effects of role responsibilities on the health functioning of African American mothers. Women \& Health, 49(2-3), 144-163. https://doi.org/10. 1080/03630240902915051

Bocciardi, F., Caputo, A., Fregonese, C., Langher, V., \& Sartori, R. (2017). Career adaptability as a strategic competence for career development: An exploratory study of its key predictors. European Journal of Training and Development, 41(1), 67-82. https:// doi.org/10.1108/EJTD-07-2016-0049

Boeri, M. W. (2004). "Hell, I'm An Addict, But I Ain't No Junkie": An Ethnographic Analysis of Aging Heroin Users. Human Organization, 63(2), 236-245. https://doi.org/10.17730/humo.63.2.p36eq ah3w46pn $8 \mathrm{t} 2$

Bollen, K. A., \& Stine, R. (1990). Direct and indirect effects: Classical and bootstrap estimates of variability. Sociological Methodology, 20,115-140. https://doi.org/10.2307/271084

Brody, E. M. (1981). "Women in the middle" and family help to older people. The Gerontologist, 21, 471-480. https://doi.org/10.1093/ geront/21.5.471

Butterfield, L. D., Borgen, W. A., Amundson, N. E., \& Erlebach, A. C. (2010). What helps and hinders workers in managing change. Journal of Employment Counseling, 47(4), 146-156. https://doi. org/10.1002/j.2161-1920.2010.tb00099.x

Celen-Demirtas, S., Konstam, V., \& Tomek, S. (2015). Leisure activities in unemployed emerging adults: Links to career adaptability and subjective well-being. The Career Development Quarterly, 63(3), 209-222. https://doi.org/10.1002/cdq.12014

Chau, P. Y. K. (1997). Reexamining a Model for Evaluating Information Center Success Using a Structural Equation Modeling Approach. Decision Sciences, 28(2), 309-334. https://doi.org/ 10.1111/j.1540-5915.1997.tb01313.x

Chong, S. H., \& Leong, F. T. L. (2015). Antecedents of career adaptability in strategic career management. Journal of Career Assessment, 25(2), 268-280. https://doi.org/10.1177/1069072715621522

Fan, X. H., Fang, X. Y., Liu, Y., Lin, X. Y., \& Yuan, X. J. (2012). The effect of social support and social identity on the relationship between perceived discrimination and socio-cultural adjustment among Chinese migrant children. Acta Psychologica Sinica, 44(5), 647-663. https://doi.org/10.3724/SP.J.1041.2012.00647

Gamble, B., \& Crouse, D. (2020). Strategies for supporting and building student resilience in Canadian secondary and post-secondary educational institutions. SciMedicine Journal, 2(2), 70-76. https:// doi.org/10.28991/SciMedJ-2020-0202-4

Goodman, J. (1994). Career adaptability in adults: A construct whose time has come. Career Development Quarterly, 43(1), 74-84. https://doi.org/10.1002/j.2161-0045.1994.tb00848.x
Greenhaus, J. H., \& Powell, G. N. (2006). When work and family are allies: A theory of work-family environments. Academy of Management Review, 31(1), 72-92. https://doi.org/10.5465/amr.2006. 19379625

Guan, Y., Dai, X., Gong, Q., Deng, Y., Hou, Y., Dong, Z., Wang, L., Huang, Z., \& Lai, X. (2017). Understanding the trait basis of career adaptability: A two-wave mediation analysis among Chinese university students. Journal of Vocational Behavior, 101, 32-42. https://doi.org/10.1016/j.jvb.2017.04.004

Guan, Y., Deng, H., Sun, J., Wang, Y., Cai, Z., Ye, L., Fu, R., Wang, Y., Zhang, S., \& Li, Y. (2013). Career adaptability, job search self-efficacy and outcomes: A three-wave investigation among Chinese university graduates. Journal of Vocational Behavior, 83(3), 561-570. https://doi.org/10.1016/j.jvb.2013.09.003

He, A. M., Bao, C. C., \& Hui, Q. P. (2020). The relationship between emotional intelligence and mental health in undergraduates: The mediating role of social support and the moderating role of mobile phone dependence. Psychological Development and Education, 36(4), 494-501. https://doi.org/10.16187/j.cnki.issn1001-4918. 2020.04 .13

Hirschi, A. (2009). Career adaptability development in adolescence: Multiple predictors and effect on sense of power and life satisfaction. Journal of Vocational Behavior, 74(2), 145-155. https://doi. org/10.1016/j.jvb.2009.01.002

Hou, Z. J., Leung, S. A., Li, X. X., Li, X., \& Xu, H. (2012). Career Adapt-Abilities Scale-China form: Construction and initial validation. Journal of Vocational Behavior, 80(3), 686-691. https:// doi.org/10.1016/j.jvb.2012.01.006

Hu, L., \& Bentler, P. M. (1999). Cutoff criteria for fit indices in covariance structure analysis: Conventional criteria versus new alternatives. Structural Equation Modeling, 6, 1-55. https://doi.org/10. 1080/10705519909540118

Jiang, Y. Z., \& Bai, X. L. (2014). College students rely on mobile Internet making impact on alienation: The role of society supporting systems. Psychological Development and Education, 30(5), 540-549.

Johnston, C. S. (2018). A Systematic Review of the Career Adaptability Literature and Future Outlook. Journal of Career Assessment, 26(1), 3-30. https://doi.org/10.1177/1069072716679921

Kelly, C. M., Strauss, K., Arnold, J., \& Stride, C. (2020). The relationship between leisure activities and psychological resources that support a sustainable career: The role of leisure seriousness and work-leisure similarity. Journal of Vocational Behavior, 117(August 2019), 103340. https://doi.org/10.1016/j.jvb.2019. 103340

Kenny, M. E., \& Bledsoe, M. (2005). Contributions of the relational context to career adaptability among urban adolescents. Journal of Vocational Behavior, 66(2), 257-272. https://doi.org/10.1016/j. jvb.2004.10.002

Koen, J., Klehe, U. C., \& Van Vianen, A. E. M. (2012). Training career adaptability to facilitate a successful school-to-work transition. Journal of Vocational Behavior, 81(3), 395-408. https:// doi.org/10.1016/j.jvb.2012.10.003

Kracke, B. (2002). The role of personality, parents and peers in adolescents. Journal of Adolescents, 25(1), 19-30. https://doi.org/ 10.1006/jado.2001.0446

Kulik, L., \& Liberman, G. (2013). Work-family conflict, resources, and role set density assessing their effects on distress among working mothers. Journal of Career Development, 40(5), 445465. https://doi.org/10.1177/0894845312467500

Kulik, L., Shilo-Levin, S., \& Liberman, G. (2015). Multiple roles, role satisfaction, and sense of meaning in life: An extended examination of role enrichment theory. Journal of Career Assessment, 23(1), 137-151. https://doi.org/10.1177/10690 72714523243 
Lang, J. C., \& Lee, C. H. (2005). Identity accumulation, others' acceptance, job-search self-efficacy, and stress. Journal of Organizational Behavior, 26(3), 293-312. https://doi.org/10. 1002/job.309

Lay-Khim, G., \& Bit-Lian, Y. (2019). Simulated patients' experience towards simulated patient-based simulation session: A qualitative study. SciMedicine Journal, 1(2), 55-63. https://doi.org/10.28991/ SciMedJ-2019-0102-3

Mai, P. P. (2017). A Study on the factors influencing college students' career adaptability - Taking $N$ University as an example (Unpublished master's thesis). Shanghai Normal University.

Marks, S. R. (1977). Multiple roles and role strain: Some notes on human energy, time and commitment. American Sociological Review, 42(6), 921-936. https://doi.org/10.2307/2094577

Marks, S. R., \& MacDermid, S. M. (1996). Multiple roles and the self: A theory of role balance. Journal of Marriage and the Family, 58(2), 417-432. https://doi.org/10.2307/353506

Martikainen, P. (1995). Women's employment, marriage, motherhood and mortality: A test of the multiple role and role accumulation hypotheses. Social Science \& Medicine, 40(2), 199-212. https:// doi.org/10.1016/0277-9536(94)E0065-Z

Meng, H., Yang, Z., Xu, L., \& Tang, C. (2012). Undergraduates' social self-efficacy and academic achievements: The mediating role of adjustment. Chinese Journal of Clinical Psychology, 20(4), 552-555. https://doi.org/10.16128/j.cnki.1005-3611.2012.04.014

Murphy, K. A., Blustein, D. L., Bohlig, A. J., \& Platt, M. G. (2010). The college-to-career transition: An exploration of emerging adulthood. Journal of Counseling \& Development, 88(2), 174181. https://doi.org/10.1002/j.1556-6678.2010.tb00006.x

Nicklin, J. M., Brown, K., \& Ketay, S. (2020). Managing multiple roles for generation stress: An exploratory investigation of positive resources impacting conflict and enrichment in college students. European Journal of Applied Positive Psychology, 4(6), 1-13.

Nordenmark, M. (2004). Multiple social roles and well-being: A longitudinal test of the role stress theory and the role expansion theory. Acta Sociologica, 47(2), 115-126. https://doi.org/10.1177/00016 99304043823

Öztemel, K., \& Yıldız-Akyol, E. (2019). The predictive role of happiness, social support, and future time orientation in career adaptability. Journal of Career Development, 1-14. https://doi.org/10. 1177/0894845319840437

Rasheed, M. I., Weng, Q., Umrani, W. A., \& Moin, M. F. (2021). Abusive supervision and career adaptability: The role of self-efficacy and coworker support. Human Performance. https://doi.org/10. 1080/08959285.2021.1928134

Rosenfeld, L. B., Richman, J. M., \& Bowen, G. L. (2000). Social support networks and school outcomes: The centrality of the teacher. Child \& Adolescent Social Work Journal, 17(3), 205-226. https:// doi.org/10.1023/A:1007535930286

Ruderman, M. N., Ohlott, P. J., Panzer, K., \& King, S. N. (2002). Benefits of Multiple Roles for Managerial Women. The Academy of Management Journal, 45(2), 369-386. https://doi.org/10.5465/ 3069352

Savickas, M. L. (1997). Career adaptability: An integrative construct for life-span, life-space theory. Career Development Quarterly, 45(3), 247-259. https://doi.org/10.1002/j.2161-0045.1997.tb004 69. $\mathrm{x}$

Savickas, M. L., \& Porfeli, E. J. (2012). Career Adapt-Abilities Scale: Construction, reliability, and measurement equivalence across 13 countries. Journal of Vocational Behavior, 80(3), 661-673. https://doi.org/10.1016/j.jvb.2012.01.011

Schwarzer, R., Bäßler, J., Kwiatek, P., Schröder, K., \& Zhang, J. X. (1997). The Assessment of Optimistic Self-beliefs: Comparison of the German, Spanish, and Chinese Versions of the General Self-efficacy Scale. Applied Psychology: An International Review, 46(1), 69-88. https://doi.org/10.1111/j.1464-0597.1997.tb01096.x
Sieber, S. D. (1974). Toward a theory of role accumulation. American Sociological Review, 39(4), 567-578. https://doi.org/10.2307/ 2094422

Seibert, S., Kraimer, M., \& Liden, R. (2001). A social capital theory of career success. Academy of Management Journal, 44(2), 219-239. https://doi.org/10.5465/3069452

Storme, M., Celik, P., \& Myszkowski, N. (2020). A forgotten antecedent of career adaptability: A study on the predictive role of withinperson variability in personality. Personality and Individual Differences, 160, 109936. https://doi.org/10.1016/j.paid.2020.109936

Tang, D. D., \& Wen, Z. L. (2020). Statistical approaches for testing common method bias: Problems and suggestions. Journal of Psychological Science, 43(1), 215-223. https://doi.org/10.16719/j. cnki.1671-6981.20200130

Thoits, P. A. (1983). Multiple Identities and psychological well-being: A reformulation and test of the social isolation hypothesis. American Sociological Review, 48(2), 174-187. https://doi.org/10.2307/ 2095103

Tian, Y., \& Fan, X. (2014). Adversity quotients, environmental variables and career adaptability in student nurses. Journal of Vocational Behavior, 85(3), 251-257. https://doi.org/10.1016/j.jvb. 2014.07.006

UN News. (2020-10-25). UN Secretary-General: Science and solidarity key to defeating the new crown. https://news.un.org/zh/story/ 2020/10/1070102

Van Vianen, A. E. M., De Pater, I. E., \& Preenen, P. T. Y. (2009). Adaptable careers: Maximizing less and exploring more. The Career Development Quarterly, 57(4), 298-309. https://doi.org/ 10.1002/j.2161-0045.2009.tb00115.x

Wang, C. K., Hu, Z. F., \& Liu, Y. (2001). Evidences for reliability and validity of the Chinese version of General Self-Efficacy Scale. Chinese Journal of Applied Psychology, 7(1), 37-40.

Wang, Z., \& Fu, Y. (2015). Social support, social comparison, and career adaptability: A moderated mediation model. Social Behavior \& Personality, 43(4), 649-659. https://doi.org/10.2224/sbp. 2015.43.4.649

Wen, H., \& Liang, Y. S. (2015). The Essence of Testing Structural Equation Models Using Popular Fit Indexes. Journal of Psychological Science, 38(4), 987-994. https://doi.org/10.16719/j.cnki. 1671-6981.2015.04.031

Wu, S. (2008). A Study of University Student's Career Adaptability Inventory (Unpublished master's thesis). National Chiayi University.

Xiao, S. Y. (1994). Theoretical basis and research application of the Social Support Rating Scale. Journal of Clinical Psychiatry, 4(2), 98-100.

Xinhua News Agency. (2020-05-12). The 2020 college graduates reach 8.74 million and hit a new record high. http://www.xinhu anet.com/politics/2020-05/12/c_1125974840.htm.

Ye, Y. M., \& Dai, X. Y. (2008). The Adolescent Social Support Scale. In X. Y. Dai (Ed.), Handbook of Common Psychological Assessment Scales (pp. 94-96). Military Science Publishing House.

Zacher, H. (2014). Individual difference predictors of change in career adaptability over time. Journal of Vocational Behavior, 84(2), 188-198. https://doi.org/10.1016/j.jvb.2014.01.001

Zhang, M. (2012). A study on the relationship between college students' role conflict and learning burnout (Unpublished master's thesis). Beijing University of Technology.

Zhang, X. E., \& Li, M. Y. (2020). Research on the driving factors of entrepreneurial resilience and its influence on entrepreneurial success. Foreign Economies \& Management, 42(8), 96-108. https:// doi.org/10.16538/j.cnki.fem.20200519.401

Publisher's Note Springer Nature remains neutral with regard to jurisdictional claims in published maps and institutional affiliations. 